Review Article

\title{
Efficacy and Safety of Xinyue Capsule for Coronary Artery Disease after Percutaneous Coronary Intervention: A Systematic Review and Meta-Analysis of Randomized Clinical Trials
}

\author{
Zhonghui Jiang $\mathbb{D}^{1,2}$ Hua Qu, ${ }^{1,2}$ Ying Zhang, ${ }^{1,2}$ Fan Zhang, ${ }^{1,2}$ Wenli Xiao, ${ }^{1,2}$ Dazhuo Shi, ${ }^{1,2}$ \\ Zhuye Gao $\mathbb{1}^{1,2}$ and Keji Chen $\mathbb{( i )}^{1,2}$ \\ ${ }^{1}$ Department of Cardiology, Xiyuan Hospital, China Academy of Chinese Medical Sciences, Beijing 100091, China \\ ${ }^{2}$ National Clinical Research Center for Chinese Medicine Cardiology, Beijing 100091, China \\ Correspondence should be addressed to Zhuye Gao; zhuyegao@126.com and Keji Chen; kjchenvip@163.com
}

Received 24 December 2020; Revised 8 March 2021; Accepted 29 March 2021; Published 9 April 2021

Academic Editor: Xu Wu

Copyright (c) 2021 Zhonghui Jiang et al. This is an open access article distributed under the Creative Commons Attribution License, which permits unrestricted use, distribution, and reproduction in any medium, provided the original work is properly cited.

\begin{abstract}
To evaluate the efficacy and safety of Xinyue capsule (XYC) in the treatment of coronary artery disease (CAD) after percutaneous coronary intervention (PCI), databases including MEDLINE, EMBASE (Ovid), PubMed, Google Scholar, Cochrane Central Register of Controlled Trials (CENTRAL), China National Knowledge Infrastructure database (CNKI), Wanfang, and VIP were searched to identify randomized controlled trials (RCTs) on XYC in CAD after PCI published before October 2020. Data extraction, methodological quality assessment, and data analysis were performed according to the Cochrane standard. Dichotomous data were shown as risk ratios (RRs) with a 95\% confidence interval (CI). All analyses were done with Review Manager, version 5.3. The quality of evidence was assessed by the Grading of Recommendations Assessment, Development and Evaluation (GRADE) approach. A total of 9 related studies from 166 related articles were identified, which included 2979 patients. Compared with conventional treatment alone (or placebo plus), XYC decreased cardiovascular events $[\mathrm{RR}=0.37,95 \%$ CI $(0.27,0.51)$, $\left.I^{2}=0 \%\right]$ (nonfatal myocardial infarction $\left[R R=0.26,95 \% \mathrm{CI}(0.10,0.70), I^{2}=0 \%\right]$, revascularization $[\mathrm{RR}=0.38,95 \% \mathrm{CI}(0.24,0.61)$, $\left.I^{2}=0 \%\right]$, and rehospitalization due to ACS $\left.\left[\mathrm{RR}=0.48,95 \% \mathrm{CI}(0.33,0.68), I^{2}=0 \%\right]\right)$ and improved cardiac function (LVEF $\left[\mathrm{RR}=6.93,95 \% \mathrm{CI}(4.99,8.87), I^{2}=81 \%\right]$, LVEDV $\left[\mathrm{RR}=-4.07,95 \% \mathrm{CI}(-5.61,-2.54), I^{2}=7 \%\right]$, and LVESV $[\mathrm{RR}=-4.32,95 \% \mathrm{CI}$ $\left.\left.(-5.90,-2.74), I^{2}=50 \%\right]\right)$ in patients after PCI. In addition, XYC reduced serum NT-pro-BNP $[\mathrm{RR}=-126.91,95 \%$ CI $(-231.51$, $-22.31), I^{2}=69 \%$ ]. However, XYC had little effect on cardiovascular death [RR $=0.47,95 \%$ CI $\left.(0.13,1.68), I^{2}=0 \%\right]$, stroke $\left[\mathrm{RR}=0.52,95 \% \mathrm{CI}(0.23,1.20), I^{2}=0 \%\right]$, heart failure $\left[\mathrm{RR}=0.53,95 \% \mathrm{CI}(0.24,1.20), I^{2}=0 \%\right]$, and quality of life $[\mathrm{RR}=-1.37,95 \%$ CI $\left.(-4.97,2.22), I^{2}=93 \%\right]$. Thus, this meta-analysis suggests that XYC has potential advantages in reducing the occurrence of cardiovascular events after PCI, improving cardiac function, and reducing serum NT-pro-BNP. This potential benefit requires a high-quality RCT to assess.
\end{abstract}

\section{Introduction}

Coronary heart disease (CHD) is a common and frequently occurring disease of the cardiovascular system that seriously endangers human health. It is the leading cause of death worldwide and contributes considerably to its morbidity $[1,2]$. Data from the Global Burden of Disease Study 2015 show that in 2015 there were 422.27 million cases of cardiovascular disease (CVD) (95\% CI: 415.53-427.87 million) and 17.92 million CVD-related deaths (95\% CI: 17.59-18.28 million CVD) [3]. The number of deaths from heart disease is projected to reach 23.3 million by 2030 [4]. Approximately $50 \%$ of the mortality associated with cardiovascular disease is due to CHD [5]. A study was conducted in collaboration with the United States, and based on the current prevalence of cardiovascular risk factors in China, it was estimated that there will be an additional 21.3 million cardiovascular patients and 7.7 million cardiovascular deaths in China 
between 2010 and 2030 [6]. The high morbidity and mortality of CHD will bring a great burden to the global society.

With the development of coronary interventional therapy and surgical techniques, the mortality rate of CHD has decreased significantly, but there is still a high incidence of major adverse cardiac events (MACEs) after stenting (2.1-19\%) [7-9]. Postoperative restenosis, stent thrombosis, heart failure, and arrhythmia, for example, are still great challenges for western medicine [10]. The combination of traditional Chinese and western medicine has potential advantages in the treatment of cardiovascular events after interventional therapy for CHD.

Xinyue capsule (XYC) is a patented Chinese herbal medicine that has been used to treat CHD for over a decade in China. XYC was approved by the Chinese Food and Drug Administration (Z20030073) for the treatment of coronary artery disease (CAD) in 2005. Panax quinquefolius saponins (PQSs) are major bioactive components in XYC, each capsule contains $100 \mathrm{mg} \mathrm{PQS}$, and XYC is taken orally, 2 capsules per time, 3 times a day [11]. Plenty of previous studies have shown that XYC could relieve myocardial ischemia, alleviate clinical symptoms, improve myocardial reperfusion after percutaneous coronary intervention (PCI), reduce recurrent angina, and exhibit other pharmacological functions [12-14], but there was little solid evidence for its efficacy and safety. To provide a comprehensive synthesis of effect estimates and quality of evidence for clinical application, a systematic review and meta-analysis of randomized trials of XYC for CAD after PCI was conducted.

\section{Materials and Methods}

2.1. Search Strategies. The meta-analysis of the clinical trial was constructed following the PRISMA guidelines $[15,16]$. Results were obtained from completed, published, randomized trials of XYC for CAD after PCI. Databases searched include MEDLINE, EMBASE (Ovid), PubMed, Google Scholar, Cochrane Central Register of Controlled Trials (CENTRAL), China National Knowledge Infrastructure database (CNKI), Wanfang, and VIP from database inception to October 2020. Two reviewers (Zhonghui Jiang and Hua Qu) independently searched through the above electronic databases. MeSH terms and free words were used reasonably through the characteristics of literature databases. The detailed searching strategies are shown in Appendices 1 and 2.

\subsection{Eligibility Criteria}

2.2.1. Types of Studies. Randomized controlled trials (RCTs) of XYC in the treatment of coronary heart disease after PCI without limitation of published language or blind methods were included. The original text (including efficacy evaluation indicators) or accurate data required for analysis can be obtained. The conference papers were excluded.

2.2.2. Types of Participants. Patients had been diagnosed with CAD by coronary angiography and had successfully undergone PCI. Age, sex, and race were not subject to appropriate restrictions.

2.2.3. Types of Interventions. The treatment group was given $\mathrm{XYC}$ alone or combined with other drugs on the basis of conventional treatment (except proprietary Chinese medicines with similar functions), and the control group was given placebo or conventional treatment. Conventional western medicines include angiotensin-converting enzyme inhibitors, antiplatelet aggregation drugs, angiotensin receptor blockers, beta-blockers, calcium antagonists, statins, and nitrates.

2.2.4. Types of Outcome Measures. (1) Primary outcomes are as follows: (1) primary cardiovascular events: cardiac death, nonfatal myocardial infarction, revascularization, heart failure, stroke, and rehospitalization due to acute coronary syndrome (ACS); (2) heart function: left ventricular ejection fraction (LVEF), left ventricular end-diastolic volume (LVEDV), left ventricular end-systolic volume (LVESV), left ventricular end-diastolic dimension (LVEDD), interventricular septum thickness (IVST), and left ventricular posterior wall thickness (LVPWT).

(2) Secondary outcomes are as follows: (1) serum $\mathrm{N}$-terminal pro-B-type natriuretic peptide (NT-pro-BNP); (2) quality of life: quality of life was assessed using a 36-item Short-Form Health Survey (SF-36); (3) adverse reaction.

2.3. Data Extraction and Analysis. Two investigators (Zhonghui Jiang and Ying Zhang) independently screened data including authors, title, publication year, inclusion and exclusion criteria, sample size, study design, baseline patients' features (age, gender, and diagnosis criteria), intervention measures (dosage, usage, and treatment duration) for the treatment group and control group, endpoint definitions, and effect measured. Any disagreements were resolved through discussion with a third investigator (Keji Chen). The authors were contacted where possible if the information was incomplete or unclear. Data was managed in accordance with the principles of the intended treatment.

2.4. Risk of Bias in Individual Studies. The Cochrane Handbook for Systematic Reviews of Interventions (updated September 2009) was used to assess the risk of bias. Three reviewers (Zhonghui Jiang, Fan Zhang, and Wenli Xiao) independently assessed seven areas of bias for each outcome: (1) randomization process, (2) allocation hiding, (3) incomplete or missing outcome data, (4) deviation from expected interventions, (5) application of the blind method in research, (6) measurement of results, and (7) selection of reporting outcome. Disagreements were resolved through discussion.

2.5. Data Synthesis and Analysis. In this meta-analysis, the clinical heterogeneity among study results was analyzed by Chi-squared $\left(\chi^{2}\right)$ test, the test level was $\alpha=0.1$, and $I^{2}$-test was used to measure the heterogeneity. Where results are homogeneous $\left(P>0.1, I^{2}<50 \%\right)$, the fixed-effects model was used 

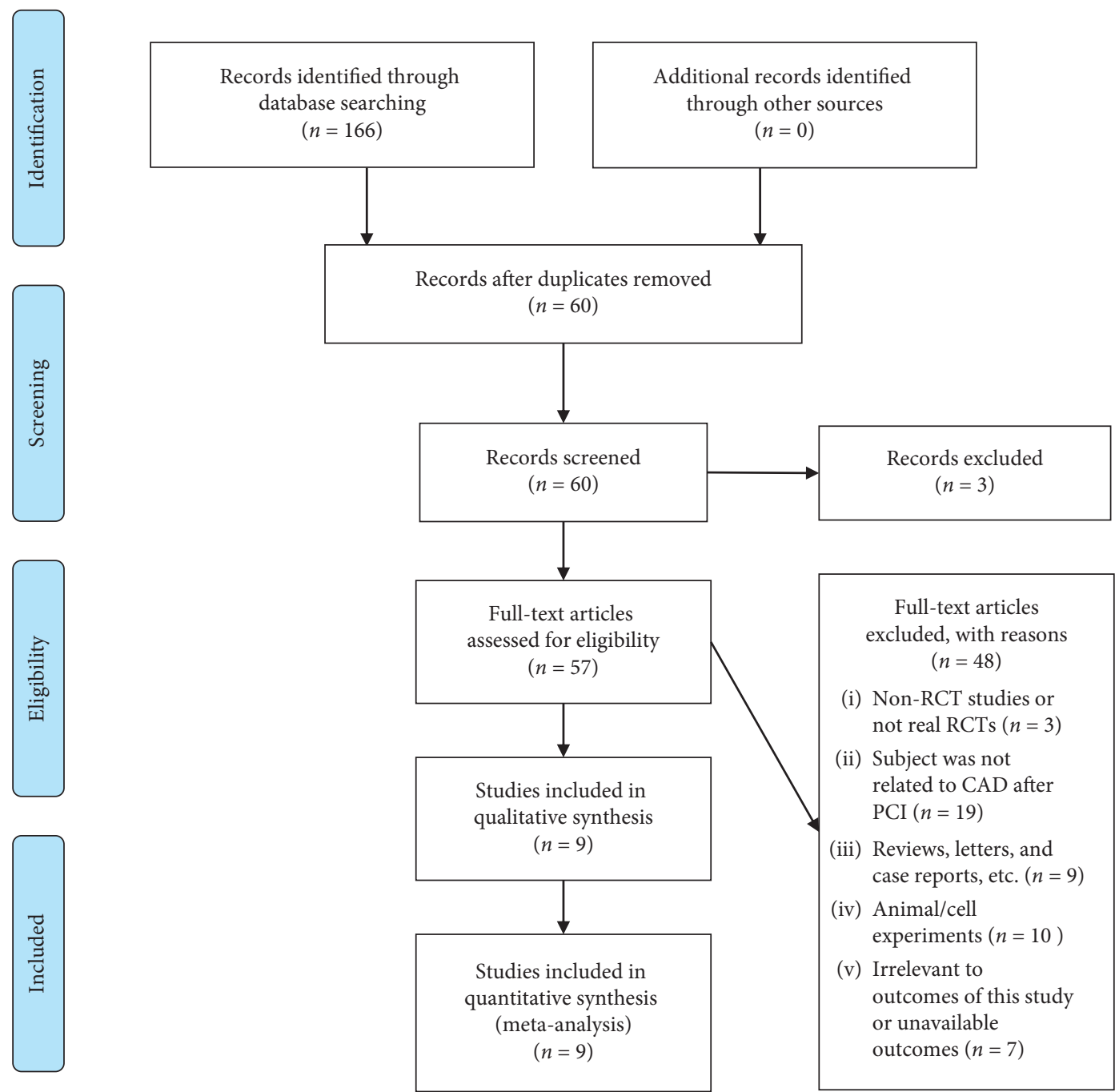

FIGURE 1: The process of the literature search and study selection.

for meta-analysis. If heterogeneity existed among the study results $\left(P \leq 0.1, I^{2} \geq 50 \%\right)$, the random-effects model was used for meta-analysis. The $Z$ test was used for the combined effect value, and the test level was $\alpha=0.05$. To estimate the size of the comprehensive effect, sensitivity analysis was performed on the meta-analysis again after eliminating individual studies. Publication bias was visually judged by drawing funnel plots and quantitative detection by using the Egger regression method, and the test level was $\alpha=0.05$. Statistical analyses were performed using the Review Manager, version 5.3. There is currently no registered protocol for this meta-analysis.

\section{Results}

3.1. Study Selection and Characteristics. As shown in Figure 1, we identified 166 potentially relevant articles from the database. After removing 106 duplicate studies, 60 studies were selected for further examination. After filtering titles and abstracts, 3 studies were excluded because of apparent disqualification. Of the remaining 57 studies, after the full-text screening, a further 48 studies were excluded. Finally, 9 studies were included in the meta-analysis.
3.2. Characteristics of Included Studies. The characteristics of the 9 included trials are shown in Table 1. Between 2010 and 2020, 9 suitable randomized controlled trials [17-25] involving 2979 participants were published, with an average sample size of 331 for each trial (ranging from 64 to 1054).

\subsection{Methodological Quality Assessment}

3.3.1. Random Sequence Generation Methods. All included studies were RCTs and mentioned the word "randomization," but 1 study [25] only mentioned the word "random" and did not report it in detail. Six studies [19-24] were of low risk and identified specific random allocation methods, including computer-generated random numbers and field stratification and random number table. However, 2 studies $[17,18]$ were high-risk and adopted randomization of treatment sequence.

3.3.2. Allocation Concealment. One study [22] used a randomized drug distribution scheme with drug number concealment, and 3 studies [20, 21, 23] adopted an opaque 
TABLE 1: Characteristics of included XYC RCTs for CAD after PCI.

\begin{tabular}{|c|c|c|c|c|c|}
\hline Study ID & $\begin{array}{l}\text { Sample size } \\
(\mathrm{T} / \mathrm{C})\end{array}$ & Age (year, T/C) & Interventions $(\mathrm{T} / \mathrm{C})$ & Duration & Outcomes \\
\hline Cao et al. [17] & $272 / 290$ & $\begin{array}{c}(58.92 \pm 11.21) / \\
(59.11 \pm 11.36)\end{array}$ & $\mathrm{XYC}+\mathrm{CWMT} / \mathrm{CWMT}$ & 6 months & (1) (2) (4) \\
\hline Chen et al. [18] & $45 / 45$ & $\begin{array}{c}(62.03 \pm 12.23) / \\
(61.25 \pm 13.46)\end{array}$ & $\begin{array}{c}\text { XYC + Fufang Chuanxiong capsule + CWMT/ } \\
\text { CWMT }\end{array}$ & 6 months & (2) \\
\hline Du et al. [19] & $60 / 62$ & $(63.20 \pm 9.20) /(60.02 \pm 10.10)$ & $\mathrm{XYC}+\mathrm{CWMT} / \mathrm{CWMT}$ & 6 months & (2) (3) \\
\hline Liu et al. [20] & $50 / 50$ & $(45 \sim 75) /(47 \sim 75)$ & $\mathrm{XYC}+\mathrm{CWMT} / \mathrm{CWMT}$ & 6 months & (1) (2) (3) \\
\hline Liu $[21]$ & $50 / 50$ & $(61.68 \pm 7.64) /(62.78 \pm 8.60)$ & $\begin{array}{c}\text { XYC + Fufang Chuanxiong capsule + CWMT/ } \\
\text { CWMT }\end{array}$ & 6 months & (1) (2) (3) \\
\hline Guo et al. [22] & $530 / 524$ & $(59.95 \pm 9.41) /(60.40 \pm 9.64)$ & $\mathrm{XYC}+\mathrm{CWMT} / \mathrm{CWMT}+$ Placebo & 24 weeks & (1) (4) (5) \\
\hline Wang et al. [23] & $404 / 404$ & $(31 \sim 75) /(35 \sim 75)$ & $\begin{array}{c}\text { XYC + Fufang Chuanxiong capsule + CWMT/ } \\
\text { CWMT }\end{array}$ & 6 months & (1) (5) \\
\hline Zhang et al. [24] & $40 / 39$ & $(48.03 \pm 7.59) /(46.83 \pm 6.38)$ & $\begin{array}{c}\text { XYC + Fufang Chuanxiong capsule + CWMT/ } \\
\text { CWMT }\end{array}$ & 6 months & (2) \\
\hline Zhao [25] & $32 / 32$ & $\begin{array}{r}(55.75 \pm 12.40) / \\
(57.30 \pm 11.89) \\
\end{array}$ & $\mathrm{XYC}+\mathrm{CWMT} / \mathrm{CWMT}+$ Placebo & 24 weeks & (2) (3) (4) \\
\hline
\end{tabular}

T/C, treatment/control; CWMT, conventional western medicine treatment; XYC (SFDA registry number: Z20030073), two capsules orally, three times daily; Fufang Chuanxiong capsule (SFDA registry number: 0802205), two capsules orally, three times daily; (1) primary cardiovascular events; (2) heart function; (3) NT-pro-BNP; (4) quality of life; (5) adverse reaction.

envelope for random allocation scheme concealment, which were considered as low risk, while the remaining 5 studies were not mentioned.

3.3.3. Blinding. Two studies [22, 25] used placebo as control and blinded both participants and personnel, which were assessed as having a low risk. One study [23] was open-label and was assessed as high risk. The outcomes of 4 studies $[20,22,23,25]$ were evaluated by a third party, so were all blind and low-risk studies. The remaining 5 studies were unclear.

3.3.4. Data Integrity. All study data were complete and were evaluated as having a low risk.

3.3.5. Other. The results of selective reporting and other biases are not clear. Risk assessments of included study bias are shown in Figures 2 and 3.

\subsection{Primary Outcomes}

3.4.1. Primary Cardiovascular Events. Based on conventional western medicine treatment, XYC alone or combined with other western medicines could effectively reduce the risk of cardiovascular events. As shown in Figure 4(a), a total of 5 trials [17, 20-23] including 2624 patients (XYC group: 1306, control group: 1318) reported the occurrence of total clinical events, indicating that the XYC group had better efficacy on lowering the cardiovascular events compared with the control group $\left[\mathrm{RR}=0.37,95 \% \mathrm{CI}(0.27,0.51), I^{2}=0 \%\right]$.

(1) Cardiac Death. Five studies [17, 20-23] reported cardiac death. There was no evidence that the XYC group was better than the control group $[\mathrm{RR}=0.47,95 \%$ CI $(0.13,1.68)$, $\left.I^{2}=0 \%\right]$, as shown in Figure $4(\mathrm{~b})$.
(2) Nonfatal Myocardial Infarction. Five studies [17, 20-23] reported nonfatal myocardial infarction; the results showed that the XYC group had a lower rate of reinfarction $\left[\mathrm{RR}=0.26,95 \% \mathrm{CI}(0.10,0.70), I^{2}=0 \%\right]$ (Figure $4(\mathrm{c})$ ).

(3) Revascularization. Three studies [17, 22, 23] described revascularization; the meta-analysis showed that the XYC group was better at lowering revascularization than the control group $\left[\mathrm{RR}=0.38,95 \% \mathrm{CI}(0.24,0.61), I^{2}=0 \%\right.$ ] (Figure $\left.4(\mathrm{~d})\right)$.

(4) Heart Failure. Four studies [17, 20, 21, 23] reported heart failure; the results showed that the difference between the two groups was not statistically significant $[R R=0.53,95 \%$ CI $(0.24,1.20), I^{2}=0 \%$ ] (Figure $4(\mathrm{e})$ ).

(5) Stroke. The incidence of stroke was observed in 5 of the studies [17, 20-23]. There was no statistical significance in stroke occurrence between the two groups $[\mathrm{RR}=0.52,95 \%$ CI $(0.23,1.20), I^{2}=0 \%$ ] (Figure $4(f)$ ).

(6) Rehospitalization due to ACS. Three studies [17, 22, 23] reported rehospitalization due to ACS. The meta-analysis showed the XYC group significantly reduced the incidence of rehospitalization due to ACS, compared with the control group $\left[\mathrm{RR}=0.48,95 \% \mathrm{CI}(0.33,0.68), I^{2}=0 \%\right]$ (Figure $\left.4(\mathrm{~g})\right)$.

\subsubsection{Heart Functions}

(1) LVEF. Seven studies [17-21, 24, 25] reported the LVEF, including 549 patients in the XYC group and 568 patients in the control group. The meta-analysis showed that the XYC group could increase the LVEF significantly $\left[\mathrm{RR}=6.93,95 \% \mathrm{CI}(4.99,8.87), I^{2}=81 \%\right]$ (Figure 5(a)). Due to high heterogeneity, the sensitivity of LVEF was analyzed. When the two studies $[17,24]$ were deleted, there was no significant change in the results $[R R=5.74,95 \%$ CI $(4.60$, 6.88), $P<0.00001$ ]. 


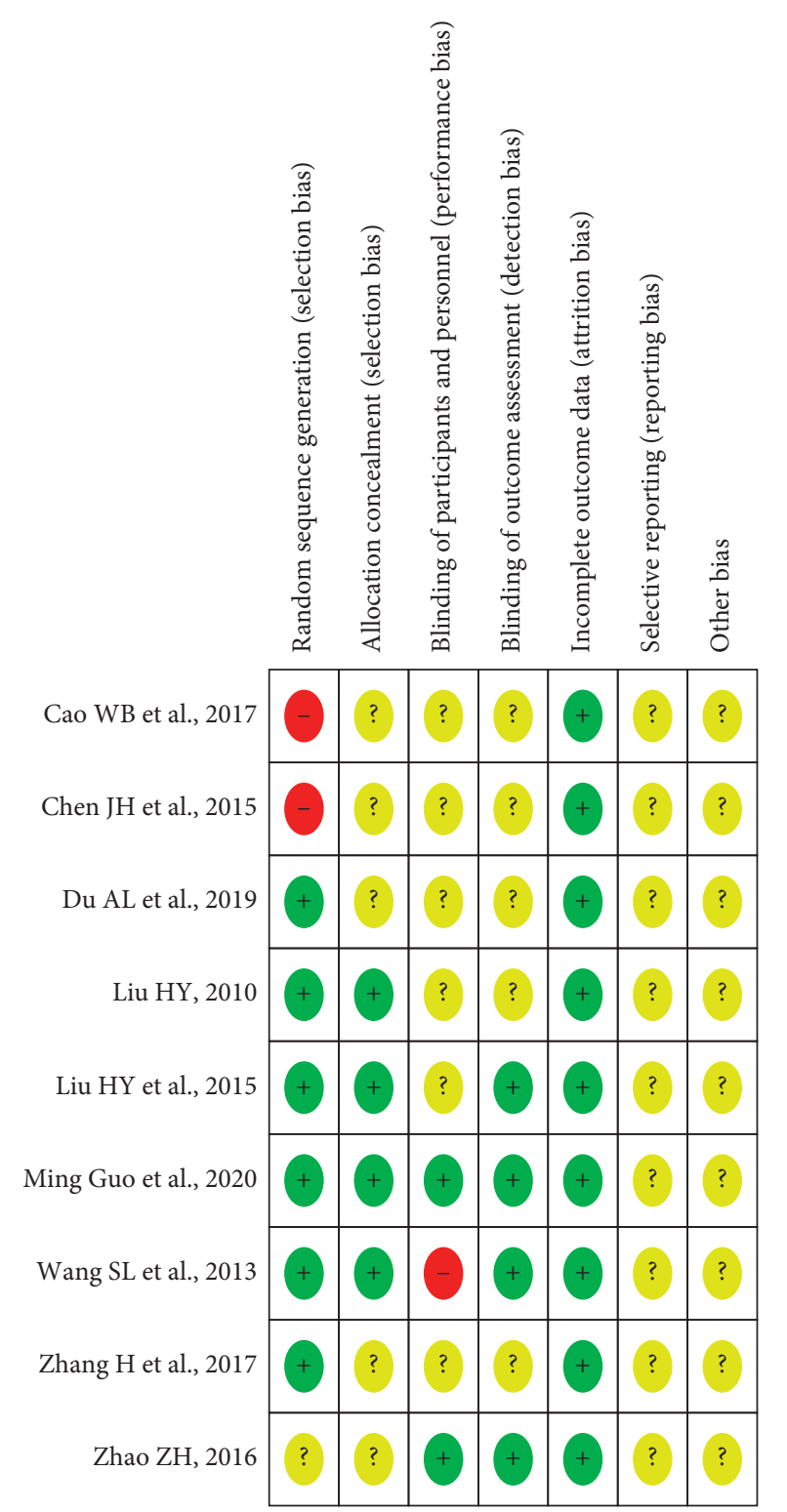

FIgURE 2: Summary of bias risk assessment for included studies.

(2) LVEDV. Five studies [17-21] reported the LVEDV, involving 974 patients. The studies showed that the XYC group could effectively regulate LVEDV compared with the control group $\left[\mathrm{RR}=-4.07,95 \% \mathrm{CI}(-5.61,-2.54), I^{2}=7 \%\right]$ (Figure 5(b)).

(3). LVESV. Five studies [17-21] reported the LVESV, involving 974 patients. The studies showed that the XYC group could effectively regulate LVESV compared with the control group $\left[\mathrm{RR}=-4.32,95 \%\right.$ CI $\left.(-5.90,-2.74), I^{2}=50 \%\right]$ (Figure 5(c)). Due to high heterogeneity, the sensitivity of LVESV was analyzed. When one of the studies [17] was deleted, there was no significant change in the results $[\mathrm{RR}=-3.64,95 \% \mathrm{CI}(-4.67,-2.62), P<0.00001]$.

(4) LVEDD. Two studies [18, 24] reported the LVEDD, involving 169 patients. There was no statistical significance in LVEDD $\left[\mathrm{RR}=-4.28\right.$, 95\% CI $(-9.88,1.31), I^{2}=96 \%$ ]
(Figure 5(d)). Due to the small number of literature available, sensitivity analysis could not be carried out.

(5) IVST. Three studies $[18,21,24]$ reported the IVST, totaling 269 patients. There was no statistical significance in IVST between groups $[\mathrm{RR}=-0.09,95 \%$ CI $(-0.40,0.22)$, $\left.I^{2}=0 \%\right]$ (Figure 5(e)).

(6) LVPWT. Two studies $[18,21]$ reported the LVPWT, including 190 patients. There was no statistical significance in LVPWT between groups $[\mathrm{RR}=-0.13,95 \% \mathrm{CI}(-0.73$, 0.46 ), $I^{2}=0 \%$ ] (Figure 5(f)).

\subsection{Secondary Outcomes}

3.5.1. Serum NT-pro-BNP. Compared with the control group, meta-analysis results of 3 studies [19-21] showed that the XYC group reduced the level of serum NT-pro-BNP $\left[\mathrm{RR}=-126.91,95 \% \mathrm{CI}(-231.51,-22.31), I^{2}=69 \%\right]$ (Figure 6). Due to the small number of literature available, sensitivity analysis could not be carried out.

3.5.2. Quality of Life. Three studies [17, 22, 25] reported the quality of life of the patients, XYC group did not show better than the control group, and there was no statistically significant difference between the two groups $[\mathrm{RR}=-1.37,95 \% \mathrm{CI}(-4.97$, 2.22), $I^{2}=93 \%$ ] (Figure 7 ). Due to the small number of literature available, sensitivity analysis could not be carried out.

3.6. Adverse Reaction. Only 2 studies [22, 23] reported the adverse events of XYC, involving 636 and 629 patients, respectively in the two groups. The most common adverse drug reactions were dyspnea, palpitations, and stomach bloating. Among them, 6 patients in the XYC group had dyspnea compared to 7 patients in the control group, 2 patients in the XYC group had palpitations compared to 1 patient in the control group, and lastly, 2 patients in the XYC group had stomach bloating whereas none of the patients in the control group had stomach bloating. Compared with the control group, the total risk rate of adverse events in the XYC group was higher (1.57\% versus $1.27 \%)$, which was mainly caused by stomach bloating (Table 2). The symptoms of stomach bloating can be tolerated after the addition of gastric mucosa-protective drugs.

3.7. Publication Biases. Because the number of studies is too insufficient to create a funnel plot, we cannot assess publication bias.

3.8. GRADE. The quality of evidence was assessed by two operators (Zhonghui Jiang and Hua Qu) using the Grading of Recommendations Assessment, Development and Evaluation (GRADE) approach (version 3.6), and most cardiovascular events were considered moderate scores. Some results showed low or very low evidence due to large interstudy heterogeneity and the small number of studies (Table 3). 


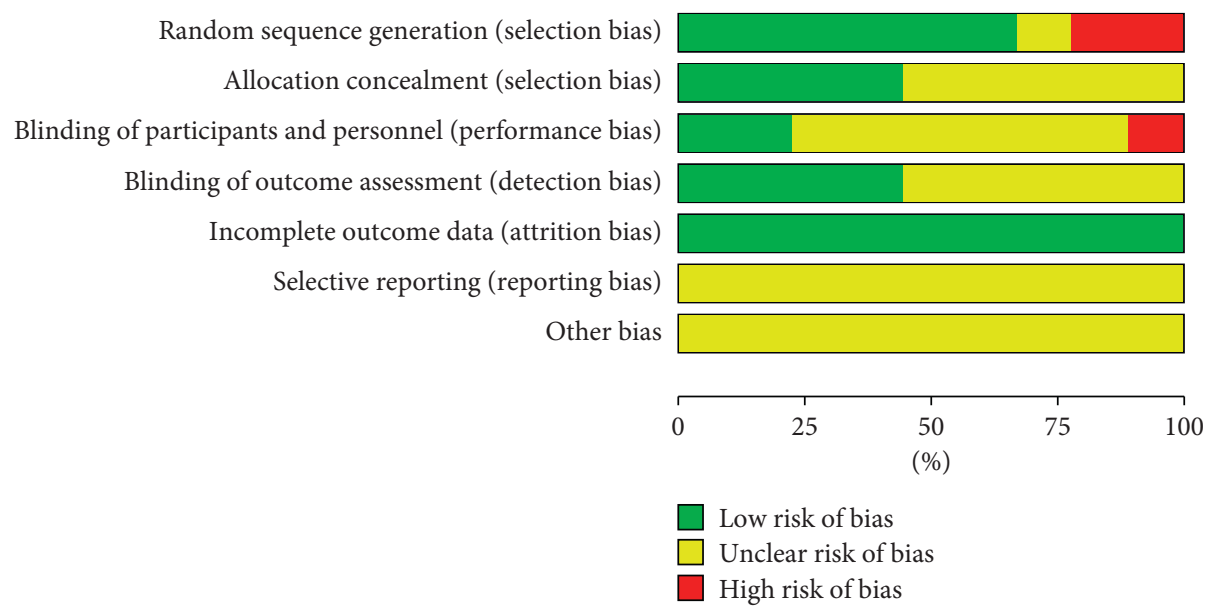

FIgURE 3: Graph of bias risk assessment for included studies.

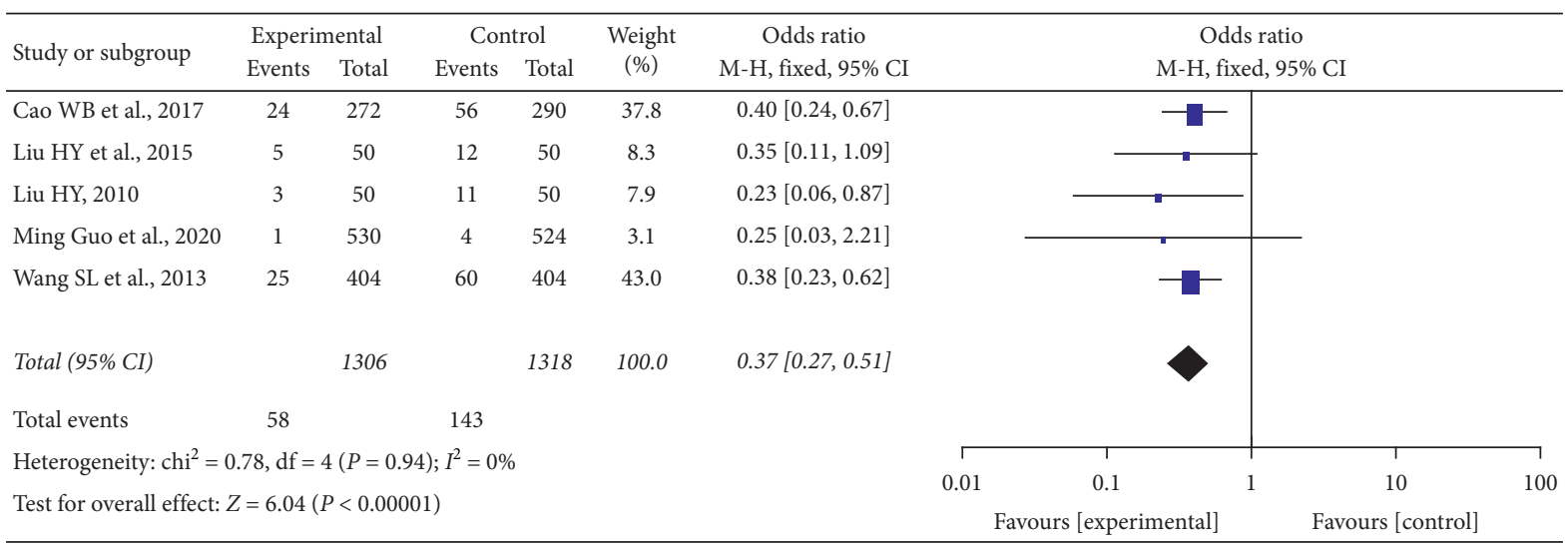

(a)

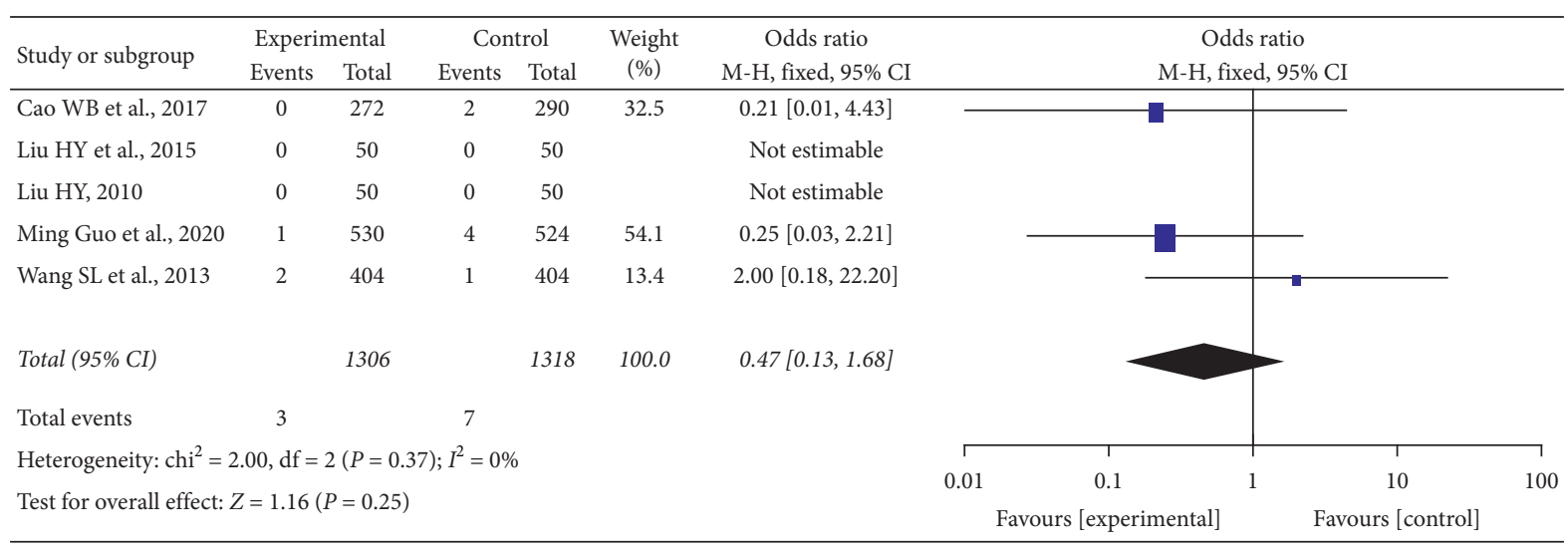

(b)

Figure 4: Continued. 


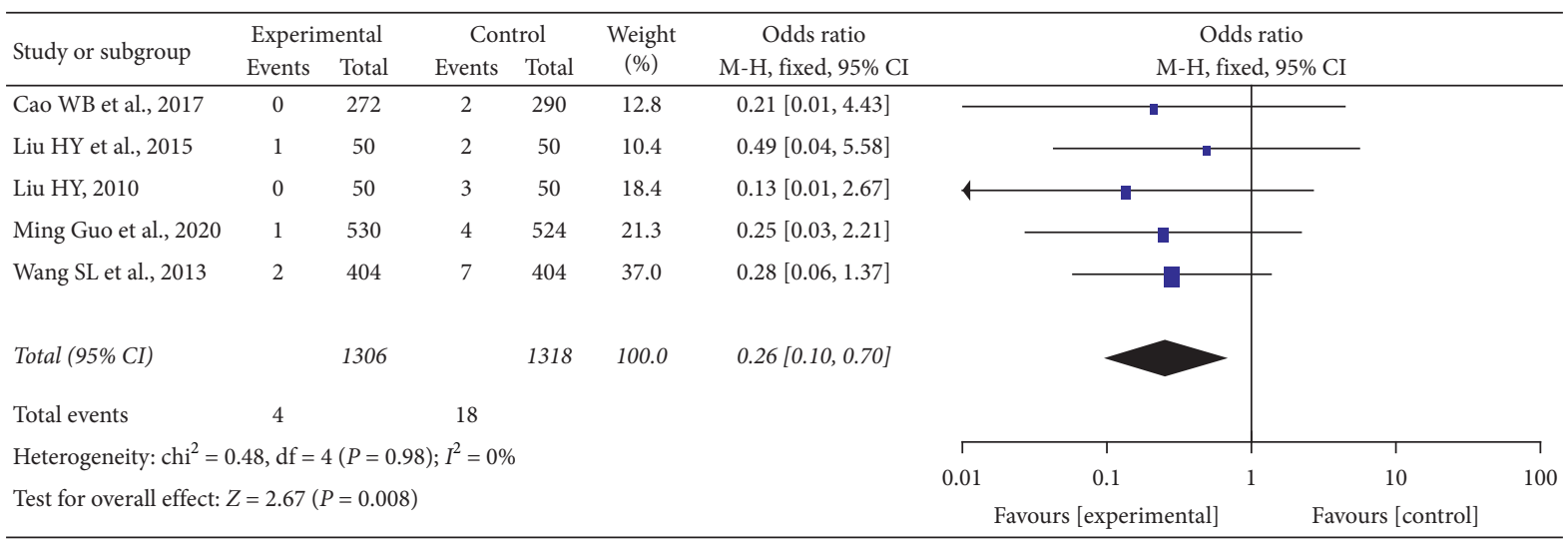

(c)

\begin{tabular}{|c|c|c|c|c|c|c|c|c|c|c|c|}
\hline \multirow{3}{*}{$\begin{array}{l}\text { Study or subgroup } \\
\text { Cao WB et al., } 2017\end{array}$} & \multicolumn{2}{|c|}{ Experimental } & \multicolumn{2}{|c|}{ Control } & \multirow{3}{*}{$\begin{array}{c}\text { Weight } \\
(\%) \\
26.7\end{array}$} & \multirow{3}{*}{$\begin{array}{c}\text { Odds ratio } \\
\text { M-H, fixed, 95\% CI } \\
0.23[0.08,0.68]\end{array}$} & \multirow{2}{*}{\multicolumn{5}{|c|}{$\begin{array}{c}\text { Odds ratio } \\
\text { M-H, fixed, } 95 \% \text { CI }\end{array}$}} \\
\hline & \multirow{2}{*}{$\frac{\text { Events }}{4}$} & \multirow{2}{*}{$\frac{\text { Total }}{272}$} & \multirow{2}{*}{$\frac{\text { Events }}{18}$} & \multirow{2}{*}{$\frac{\text { Total }}{290}$} & & & & & & & \\
\hline & & & & & & & & & & & \\
\hline Ming Guo et al., 2020 & 14 & 530 & 26 & 524 & 39.7 & $0.52[0.27,1.01]$ & & & & & \\
\hline Wang SL et al., 2013 & 8 & 404 & 22 & 404 & 33.6 & $0.35[0.15,0.80]$ & & & & & \\
\hline Total (95\% CI) & & 1206 & & 1218 & 100.0 & $0.38[0.24,0.61]$ & & & & & \\
\hline Total events & 26 & & 66 & & & & & & & & \\
\hline Heterogeneity: chi $^{2}=$ & $.76, \mathrm{df}=$ & $(P=C$ & ); $I^{2}=0$ & & & & $\Gamma$ & 1 & & 1 & \\
\hline Test for overall effect: & $=4.06$ & $<0.0$ & & & & & & 0.1 & & 10 & 100 \\
\hline
\end{tabular}

(d)

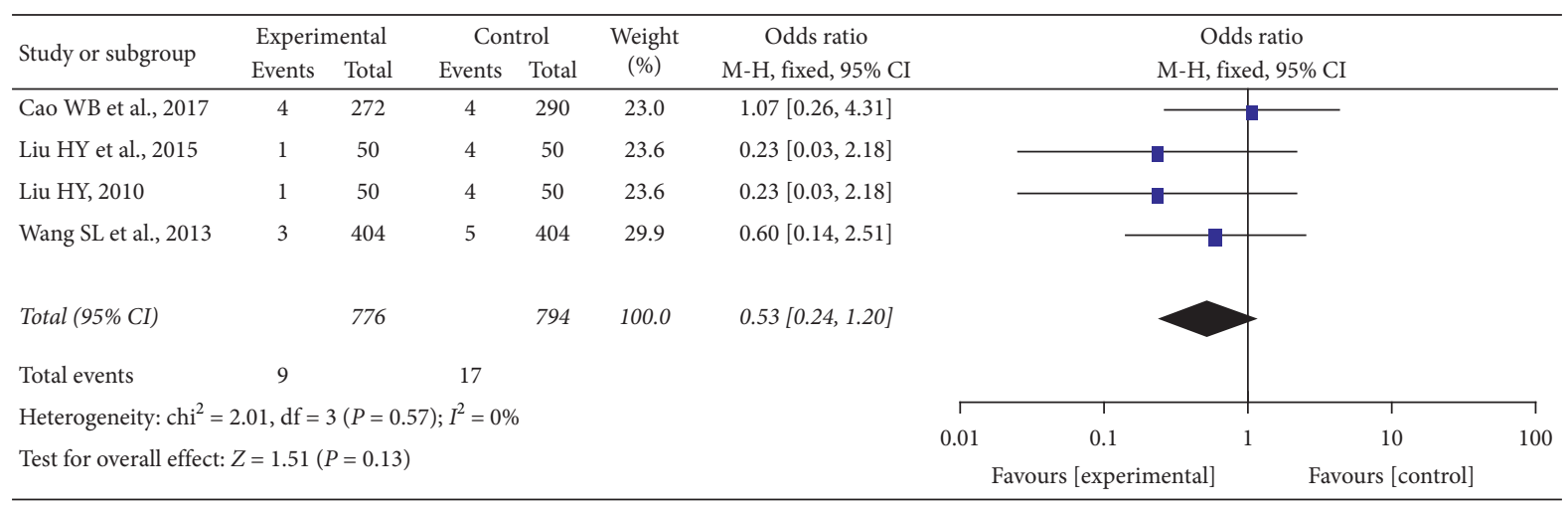

(e)

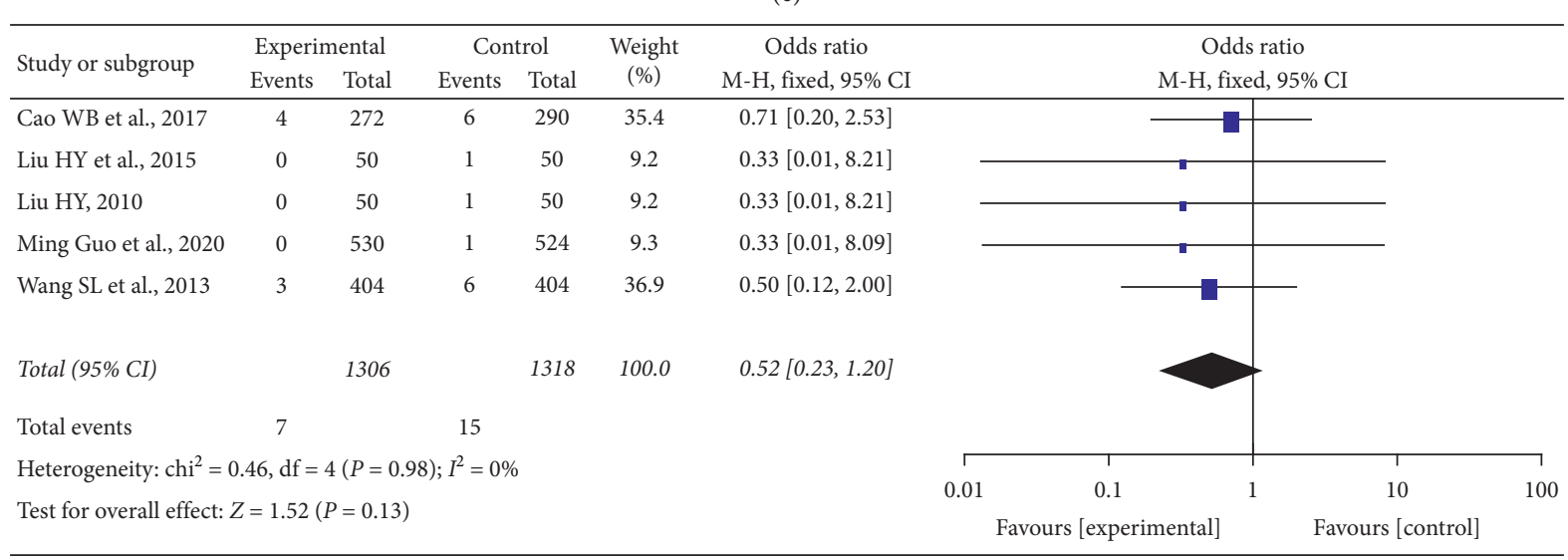

(f)

Figure 4: Continued. 


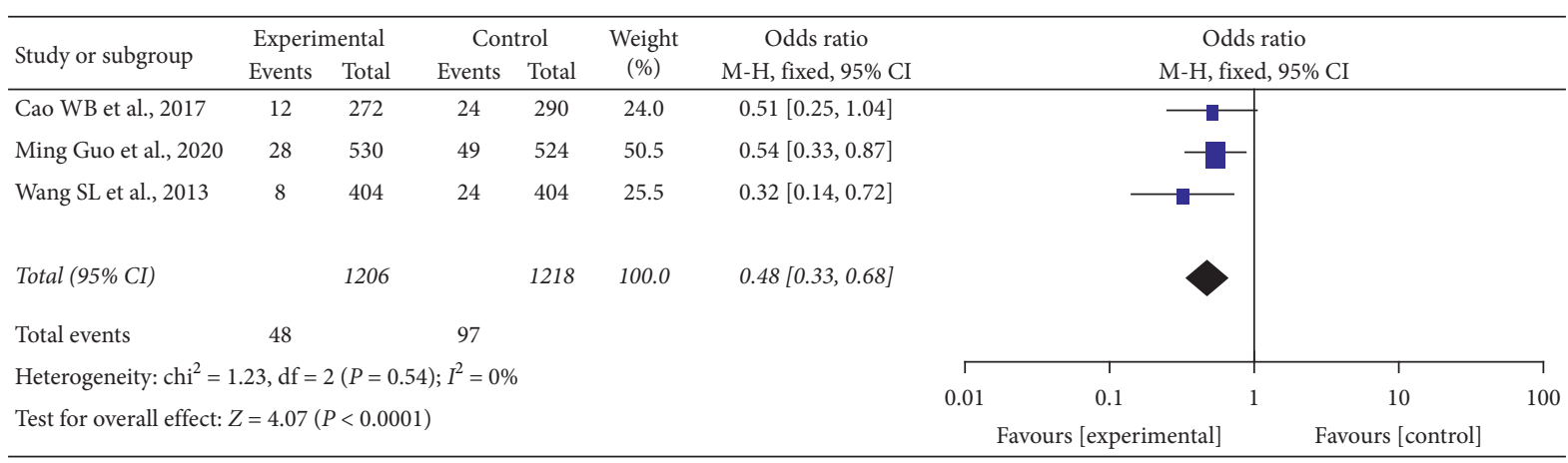

(g)

Figure 4: Primary cardiovascular events.

\begin{tabular}{|c|c|c|c|c|c|c|c|c|c|c|c|c|}
\hline \multirow{3}{*}{$\begin{array}{l}\text { Study or subgroup } \\
\text { Cao WB et al., } 2017\end{array}$} & \multicolumn{3}{|c|}{ Experimental } & \multicolumn{3}{|c|}{ Control } & \multirow{3}{*}{$\begin{array}{c}\text { Weight } \\
(\%)\end{array}$} & \multirow{3}{*}{$\begin{array}{c}\text { Mean difference } \\
\text { IV, random, 95\% CI } \\
8.81[7.19,10.43]\end{array}$} & \multirow{2}{*}{\multicolumn{3}{|c|}{$\begin{array}{l}\text { Mean difference } \\
\text { IV, random, } 95 \% \text { CI }\end{array}$}} & \\
\hline & \multirow{2}{*}{$\begin{array}{c}\text { Mean } \\
51.12\end{array}$} & \multirow{2}{*}{$\frac{\mathrm{SD}}{10.12}$} & \multirow{2}{*}{$\frac{\text { Total }}{272}$} & \multirow{2}{*}{$\begin{array}{l}\text { Mean } \\
42.31\end{array}$} & \multirow{2}{*}{$\frac{\mathrm{SD}}{9.46}$} & \multirow{2}{*}{$\begin{array}{c}\text { Total } \\
290\end{array}$} & & & & & & \\
\hline & & & & & & & & & & & $=$ & \\
\hline Chen JH et al., 2015 & 64.18 & 5.21 & 45 & 58.26 & 6.35 & 45 & 14.1 & $5.92[3.52,8.32]$ & & & 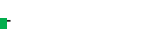 & \\
\hline Du AL et al., 2019 & 57.75 & 7.63 & 60 & 53.18 & 8.56 & 62 & 12.9 & $4.57[1.69,7.45]$ & & & $r$ & \\
\hline Liu HY et al., 2015 & 69.28 & 5.91 & 50 & 62.91 & 6.43 & 50 & 14.1 & $6.37[3.95,8.79]$ & & & + & \\
\hline Liu HY, 2010 & 65.62 & 5.15 & 50 & 58.45 & 6.47 & 50 & 14.4 & $7.17[4.88,9.46]$ & & & + & \\
\hline Zhang H et al., 2017 & 57.03 & 4.01 & 40 & 46.01 & 4.02 & 39 & 15.7 & $11.02[9.25,12.79]$ & & & 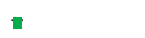 & \\
\hline Zhao ZH, 2016 & 63.25 & 6.73 & 32 & 59.85 & 5.15 & 32 & 12.8 & $3.40[0.46,6.34]$ & & 5 & & \\
\hline Total (95\% CI) & & & 549 & & & 568 & 100.0 & $6.93[4.99,8.87]$ & & & 1 & \\
\hline Heterogeneity: $\operatorname{tau}^{2}=$ & $46 ; \operatorname{chi}^{2}$ & $=31.5$ & $\mathrm{df}=6$ & $(P<0.0$ & $001) ; I^{2}$ & $2=81 \%$ & & $\begin{array}{c}\Gamma \\
-100\end{array}$ & $\begin{array}{c}1 \\
-50\end{array}$ & & $\begin{array}{c}1 \\
50\end{array}$ & $\overrightarrow{100}$ \\
\hline Test for overall effect & $=6.99$ & $(P<0.0$ & 0001) & & & & & & {$[$ expe } & & Favours [c & \\
\hline
\end{tabular}

(a)

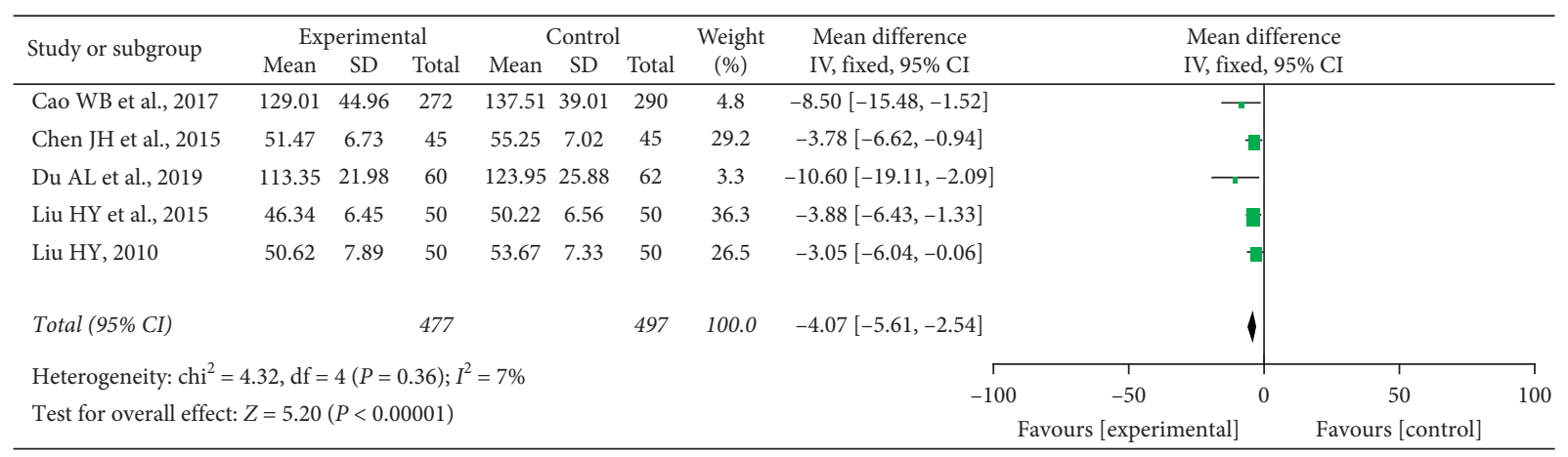

(b)

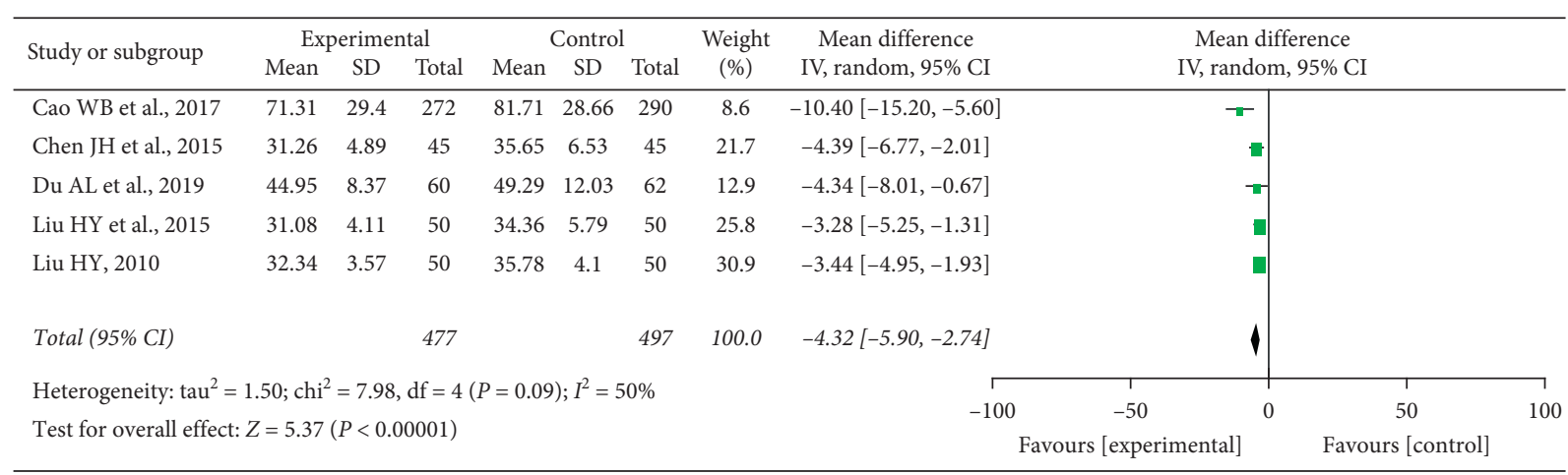

(c)

FIgure 5: Continued. 


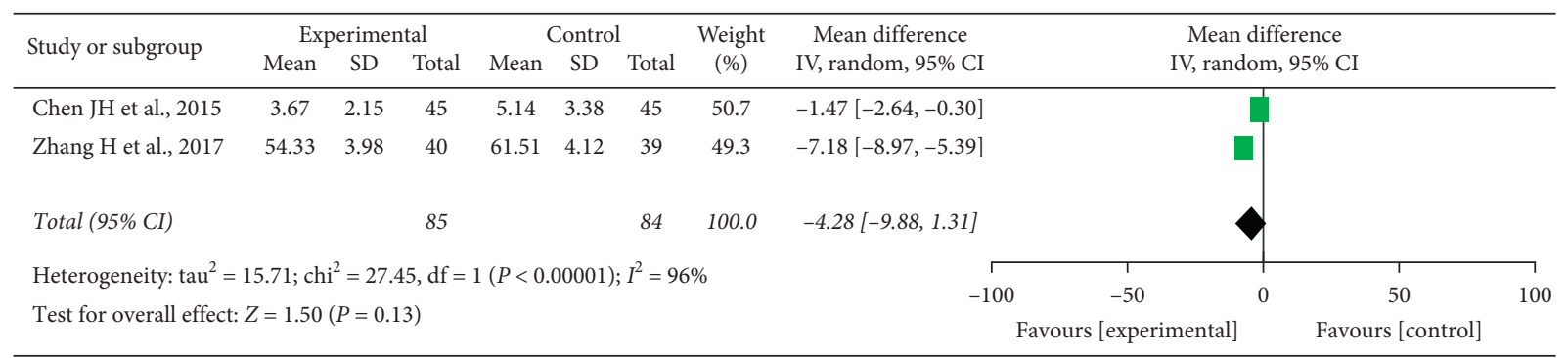

(d)

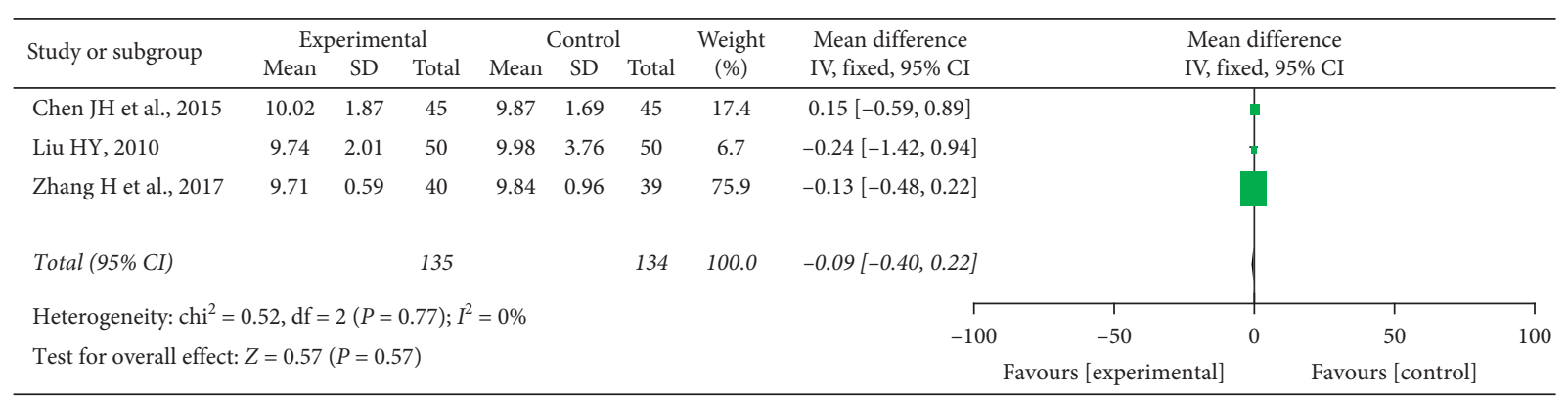

(e)

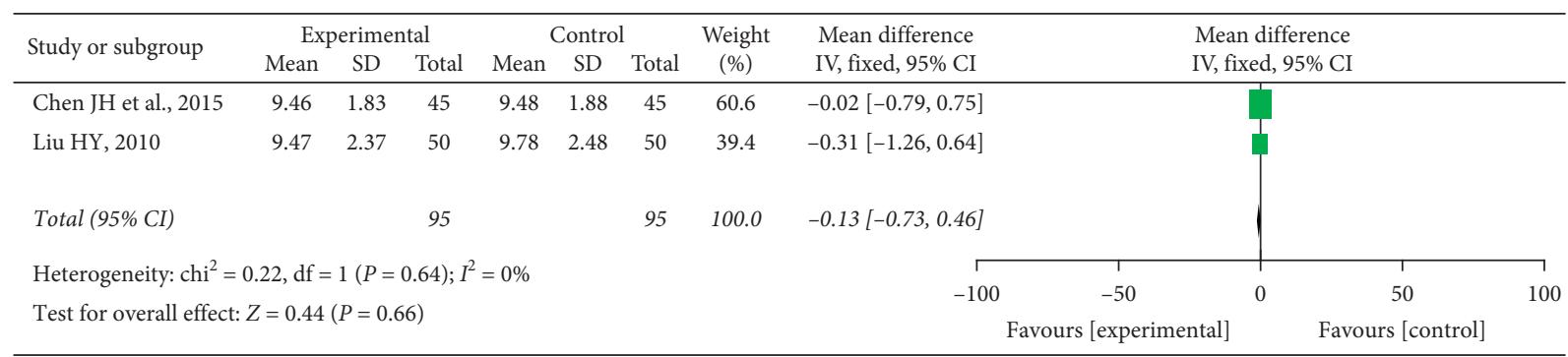

(f)

Figure 5: Heart function.

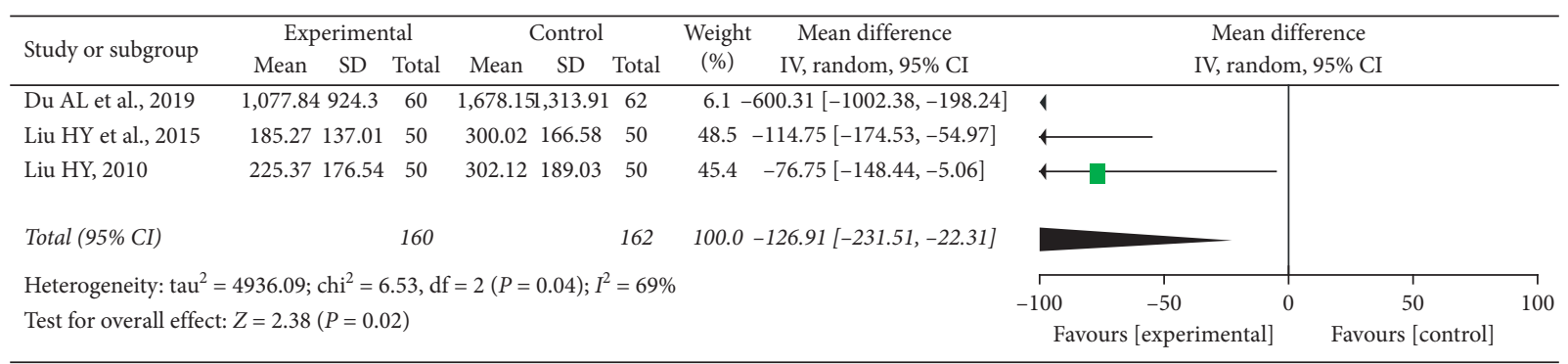

Figure 6: NT-pro-BNP.

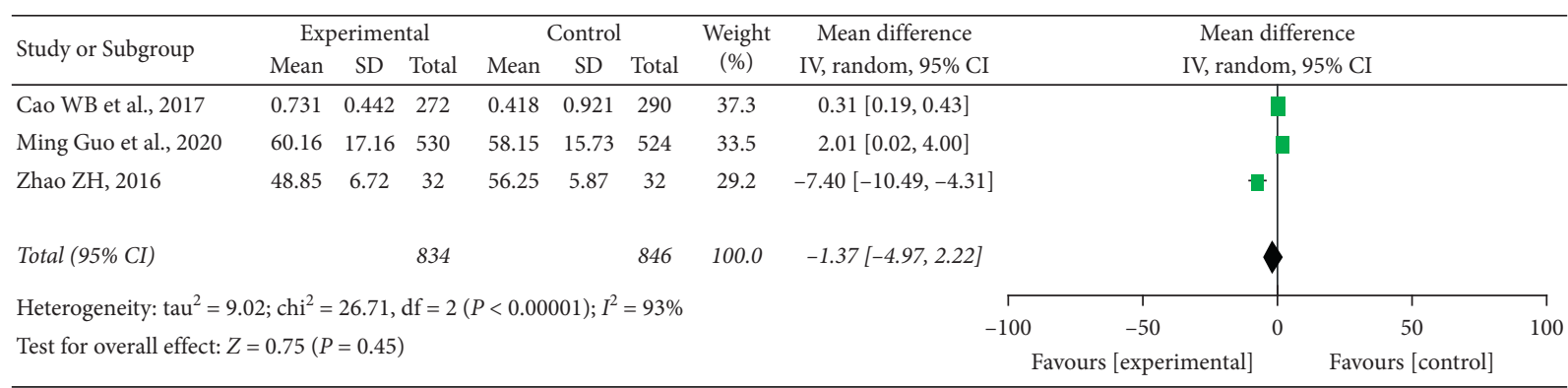

Figure 7: Quality of life. 
TABLE 2: The adverse reaction of two included studies.

\begin{tabular}{lcc}
\hline Adverse events & Treatment group (636) & Control group (629) \\
\hline Dyspnea & 6 & 7 \\
Palpitation & 2 & 1 \\
Stomach bloating & 2 & 0 \\
Total risk rate (\%) & 1.57 & 1.27 \\
\hline
\end{tabular}

TABLE 3: GRADE (quality of evidence) summary.

\begin{tabular}{|c|c|c|c|c|c|}
\hline Outcomes & $\begin{array}{l}\text { Illustrative comparative risks } \\
\text { Assumed risk } \\
\text { Control group }\end{array}$ & $\begin{array}{l}\text { Corresponding } \\
\text { risk } \\
\text { Treatment group }\end{array}$ & $\begin{array}{l}\text { Relative } \\
\text { effect }(95 \% \\
\text { CI) }\end{array}$ & $\begin{array}{l}\text { No. of } \\
\text { participants } \\
\text { (studies) }\end{array}$ & $\begin{array}{c}\text { Quality of the } \\
\text { evidence (GRADE) }\end{array}$ \\
\hline \multirow{3}{*}{$\begin{array}{l}\text { Primary } \\
\text { cardiovascular events }\end{array}$} & Study population & & \multirow{3}{*}{$\begin{array}{l}\text { RR } 0.42(0.31 \\
\quad \text { to } 0.56)\end{array}$} & \multirow{3}{*}{ 2,624 (5 studies) } & \multirow{3}{*}{$\oplus \oplus \oplus \ominus$ moderate $\mathrm{a}^{\mathrm{a}}$} \\
\hline & 108 per 1,000 & $\begin{array}{c}46 \text { per } 1,000 \text { (34 to } \\
61)\end{array}$ & & & \\
\hline & 193 per 1,000 & $\begin{array}{c}81 \text { per } 1,000(60 \text { to } \\
108)\end{array}$ & & & \\
\hline Cardiac death & $\begin{array}{l}\text { Study population } \\
5 \text { per } 1,000 \\
\text { Moderate }\end{array}$ & 3 per 1,000 (1 to 9$)$ & \multirow[t]{2}{*}{$\begin{array}{c}\text { OR } 0.47 \\
(0.13 \text { to } 1.68)\end{array}$} & \multirow[t]{2}{*}{ 2,624 (5 studies) } & \multirow[t]{2}{*}{$\oplus \oplus \oplus \ominus$ moderate ${ }^{\mathrm{a}}$} \\
\hline \multirow{3}{*}{$\begin{array}{l}\text { Nonfatal myocardial } \\
\text { infarction }\end{array}$} & $\frac{3 \text { per } 1,000}{\text { Study population }}$ & 1 per $1,000(0$ to 5$)$ & & & \\
\hline & $\begin{array}{l}14 \text { per } 1,000 \\
\text { Moderate }\end{array}$ & $\begin{array}{c}4 \text { per } 1,000(1 \text { to } \\
10)\end{array}$ & \multirow[t]{2}{*}{$\begin{array}{l}\text { OR } 0.26(0.1 \\
\quad \text { to } 0.7)\end{array}$} & \multirow[t]{2}{*}{2,624 (5 studies) } & \multirow[t]{2}{*}{$\oplus \oplus \oplus \ominus$ moderate $\mathrm{a}^{\mathrm{a}}$} \\
\hline & 17 per 1,000 & $\begin{array}{c}4 \text { per } 1,000 \text { (2 to } \\
12)\end{array}$ & & & \\
\hline \multirow{3}{*}{ Revascularization } & Study population & & \multirow{3}{*}{$\begin{array}{c}\text { OR } 0.38 \\
(0.24 \text { to } 0.61)\end{array}$} & \multirow{3}{*}{ 2,424 (3 studies) } & \multirow{3}{*}{$\oplus \oplus \Theta \Theta \mathrm{low}^{\mathrm{a}, \mathrm{c}}$} \\
\hline & $\begin{array}{l}54 \text { per } 1,000 \\
\text { Moderate }\end{array}$ & $\begin{array}{c}21 \text { per } 1,000 \text { (14 to } \\
34)\end{array}$ & & & \\
\hline & 55 per 1,000 & $\begin{array}{c}22 \text { per } 1,000 \text { (14 to } \\
34)\end{array}$ & & & \\
\hline \multirow{3}{*}{ Heart failure } & Study population & & \multirow{3}{*}{$\begin{array}{c}\text { OR } 0.53 \\
(0.24 \text { to } 1.2)\end{array}$} & \multirow{3}{*}{1,570 (4 studies) } & \multirow{3}{*}{$\oplus \oplus \oplus \ominus$ moderate ${ }^{\mathrm{a}}$} \\
\hline & $\begin{array}{l}21 \text { per } 1,000 \\
\text { Moderate }\end{array}$ & $\begin{array}{l}11 \text { per } 1,000 \text { (5 to } \\
26)\end{array}$ & & & \\
\hline & 47 per 1,000 & $\begin{array}{c}25 \text { per } 1,000 \text { (12 to } \\
56)\end{array}$ & & & \\
\hline \multirow{3}{*}{ Stroke } & Study population & & \multirow{3}{*}{$\begin{array}{c}\text { OR } 0.52 \\
(0.23 \text { to } 1.2)\end{array}$} & \multirow{3}{*}{ 2,624 (5 studies) } & \multirow{3}{*}{$\oplus \oplus \oplus \Theta$ moderate $\mathrm{a}^{\mathrm{a}}$} \\
\hline & $\begin{array}{r}11 \text { per } 1,000 \\
\text { Moderate }\end{array}$ & $\begin{array}{c}6 \text { per } 1,000 \text { (3 to } \\
14)\end{array}$ & & & \\
\hline & 20 per 1,000 & $\begin{array}{c}11 \text { per } 1,000 \text { (5 to } \\
24)\end{array}$ & & & \\
\hline \multirow{3}{*}{$\begin{array}{l}\text { Rehospitalization due } \\
\text { to ACS }\end{array}$} & Study population & & \multirow{3}{*}{$\begin{array}{c}\text { OR } 0.48 \\
(0.33 \text { to } 0.68)\end{array}$} & \multirow{3}{*}{2,424 (3 studies) } & \multirow{3}{*}{$\oplus \oplus \Theta \Theta l o w$ a, c } \\
\hline & $\begin{array}{r}80 \text { per } 1,000 \\
\text { Moderate }\end{array}$ & $\begin{array}{c}40 \text { per } 1,000(28 \text { to } \\
56)\end{array}$ & & & \\
\hline & 83 per 1,000 & $\begin{array}{c}42 \text { per } 1,000 \text { (29 to } \\
58)\end{array}$ & & & \\
\hline LVEF & $\begin{array}{c}\text { The mean LVEF in the intervention } \\
\text { groups was } 7.68 \text { higher ( } 6.85 \text { to } 8.5 \\
\text { higher) }\end{array}$ & & & 1,117 (7 studies) & $\oplus \oplus \Theta \Theta$ low $^{\text {a, b }}$ \\
\hline LVEDV & $\begin{array}{l}\text { The mean LVEDV in the } \\
\text { intervention groups was } 4.07 \text { lower } \\
\text { (5.61 to } 2.54 \text { lower) }\end{array}$ & & & 974 (5 studies) & $\oplus \oplus \oplus \ominus$ moderate $\mathrm{a}^{\mathrm{a}}$ \\
\hline
\end{tabular}


TABLE 3: Continued.

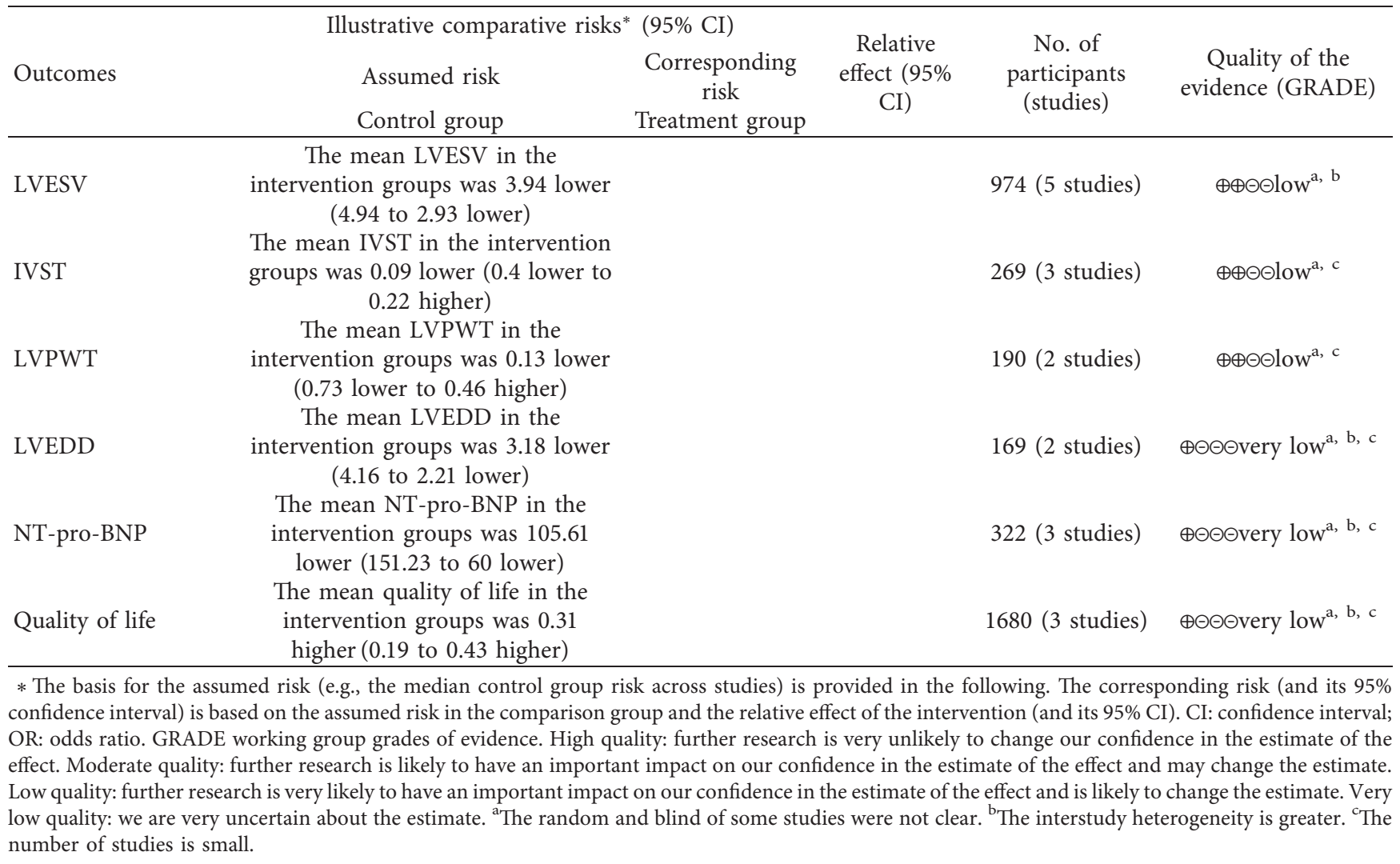

\section{Discussion}

To our knowledge, this is the first meta-analysis to evaluate the efficacy and safety of XYC in the treatment of CAD after PCI. All 9 eligible studies were based on Chinese participants. As far as we know, XYC is mainly conducted in China, and there are no relevant trials evaluating XYC in other countries except China. In this meta-analysis, it was found that XYC had potential advantages in decreasing the occurrence of cardiovascular events (nonfatal myocardial infarction, revascularization, and readmission due to ACS) as well as improving cardiac function (LVEF, LVEDV, and LVESV) in patients after PCI. XYC can also reduce the serum NT-pro-BNP. However, XYC was ultimately found to have little effect on cardiovascular death, stroke, heart failure, and quality of life.

There are several limitations in our meta-analysis that need to be noted. First, due to the limited number of studies and patients included in these studies, the results of the meta-analysis may have certain limitations in persuasiveness. Second, it is not clear whether the efficacy of XYC is related to the interaction of conventional drugs, due to the existence of conventional drug therapy in treatments and the differences in conventional drug therapies among different studies. Third, some studies lacked specific descriptions of their research design, the generation of random sequences, randomization concealment, measurement of main results, blind methods, etc. Fourth, the adverse reactions of XYC were rarely described. Fifth, there are few studies on sample size calculation. In addition, the patients included in our systematic review were all from China, so it was difficult to determine the influence of race and region.

Acute myocardial infarction (AMI) is the most common CVD, and an estimated 7 million people worldwide suffer each year [26]. As a result of this global health burden, there has been a considerable strain on the global economy. Coronary heart disease mortality has been steadily declining in most developed countries over the past 30 years. This is primarily due to vascular reconstructive surgeries such as PCI and coronary artery bypass grafting (CABG), as well as significant advances in pharmacological treatment $[27,28]$. However, the occurrence of cardiac adverse events after PCI is still a problem that cannot be ignored, which seriously affects the quality of life and prognosis of patients. Therefore, it is essential and significant to prevent cardiac adverse events after PCI. Several studies [29-31] have found that the active ingredients contained in XYC have antimyocardial ischemia, antiatherosclerosis, and antiarrhythmic effects, while regulating blood lipids, stabilizing plaque, and lowering blood pressure. Meanwhile, relevant studies have also shown that it can improve ventricular remodeling, protect cardiac function, and reduce ischemia-reperfusion injury [32-35]. According to our results, XYC may have a protective effect on the recurrence of cardiovascular events, cardiac function, and NT-pro-BNP in patients after PCI, which is consistent with the above studies.

Although this study has some limitations, its significance for clinical application and future research should be paid 
more attention. In future studies, we suggest that the trial protocols should be registered before conducting clinical studies, the trial design should strictly follow the principle of randomization and be double-blinded, the sample size should be strictly calculated, and the safety and adverse effects of the drug should be reasonably evaluated. Since the patients included in the systematic review were all from China, future studies should be international, and outpatients should also be considered. In the future, large samples and high-quality RCTs are still needed to further demonstrate the efficacy and safety of XYC, and we will continue to follow up this study. In the future, high-quality RCTs with large samples, rigorous design, and accurate reporting will be needed to enhance the power of evidence for the efficacy and safety of XYC. Thus, follow-up studies will be conducted.

\section{Conclusions}

$\mathrm{XYC}$ has potential advantages in reducing the occurrence of cardiovascular events after PCI, improving both cardiac function and NT-pro-BNP. However, some studies have shown a significant risk of bias. Therefore, in clinical treatment, it is suggested that doctors should reasonably adopt treatment strategies according to the specific conditions of patients.

\section{Abbreviations}

$\begin{array}{ll}\text { CAD: } & \text { Coronary artery disease } \\ \text { PCI: } & \text { Percutaneous coronary intervention } \\ \text { MACEs: } & \text { Major adverse cardiac events } \\ \text { XYC: } & \text { Xinyue capsule } \\ \text { PQS: } & \text { Panax quinquefolius saponin } \\ \text { CENTRAL: } & \text { Cochrane Central Register of Controlled Trials } \\ \text { CNKI: } & \text { China National Knowledge Infrastructure } \\ & \text { database } \\ \text { RCTs: } & \text { Randomized controlled trials } \\ \text { ACS: } & \text { Acute coronary syndrome } \\ \text { LVEF: } & \text { Left ventricular ejection fraction } \\ \text { LVEDV: } & \text { Left ventricular end-diastolic volume } \\ \text { LVESV: } & \text { Left ventricular end-systolic volume } \\ \text { LVEDD: } & \text { Left ventricular end-diastolic dimension } \\ \text { IVST: } & \text { Interventricular septum thickness } \\ \text { LVPWT: } & \text { Left ventricular posterior wall thickness } \\ \text { CI: } & \text { Confidence interval } \\ \text { RR: } & \text { The relative risk } \\ \text { PRISMA: } & \text { Preferred reporting items for systematic } \\ & \text { reviews and meta-analyses. }\end{array}$

\section{Conflicts of Interest}

The authors declare that they have no conflicts of interest.

\section{Authors' Contributions}

Zhonghui Jiang and Zhuye Gao put forward the idea of this study and designed the method of this systematic review. Zhonghui Jiang, Hua Qu, Ying Zhang, Fan Zhang, and Wenli Xiao searched the articles, conducted data collection and extraction, and analyzed the data. Dazhuo Shi and Keji Chen provided guidelines for this systematic review and meta-analysis. The authors approved the final version of the manuscript.

\section{Acknowledgments}

This research was financially supported by the National Science and Technology Major Project of the Ministry of Science and Technology of China (2019ZX09201005-002006), Beijing Traditional Chinese Mediund Project (JJ-202079), and the Capital Health Research and Development of Special (2018-1-4171).

\section{Supplementary Materials}

Appendix 1: search strategies for the English language databases. Appendix 2: search strategies for the Chinese databases. (Supplementary Materials)

\section{References}

[1] GBD 2016 Causes of Death Collaborators, "Global, regional, and national age-sex specific mortality for 264 causes of death, 1980-2016: a systematic analysis for the global burden of disease study 2016," The Lancet, vol. 390, no. 10100, pp. 1151-1210, 2017.

[2] G. Danaei, M. M. Finucane, Y. Lu et al., "National, regional, and global trends in fasting plasma glucose and diabetes prevalence since 1980: systematic analysis of health examination surveys and epidemiological studies with 370 countryyears and 2.7 million participants," The Lancet, vol. 378, no. 9785, pp. 31-40, 2011.

[3] G. A. Roth, C. Johnson, A. Abajobir et al., "Global, regional, and national burden of cardiovascular diseases for 10 causes, 1990 to 2015," Journal of the American College of Cardiology, vol. 70, no. 1, pp. 1-25, 2017.

[4] S. Bansilal, J. M. Castellano, and V. Fuster, "Global burden of CVD: focus on secondary prevention of cardiovascular disease," International Journal of Cardiology, vol. 201, pp. S1-S7, 2015.

[5] D. Lloyd-Jones, R. Adams, M. Carnethon et al., "Heart disease and stroke statistics-2009 update: a report from the American heart association statistics committee and stroke statistics subcommittee," Circulation, vol. 119, pp. e21-e181, 2009.

[6] A. Moran, D. Gu, D. Zhao et al., "Future cardiovascular disease in China: markov model and risk factor scenario projections from the coronary heart disease policy modelChina," Circulation: Cardiovascular Quality and Outcomes, vol. 3, no. 3, pp. 243-252, 2010.

[7] R. Moreno, E. García, R. Teles et al., "Randomized comparison of sirolimus-eluting and everolimus-eluting coronary stents in the treatment of total coronary occlusions: results from the chronic coronary occlusion treated by everolimus-eluting stent randomized trial," Circulation: Cardiovascular Interventions, vol. 6, no. 1, pp. 21-28, 2013.

[8] J. H. Ahn, J. H. Yang, C. W. Yu et al., "First-generation versus second-generation drug-eluting stents in coronary chronic total occlusions: two-year results of a multicenter registry," PLoS One, vol. 11, no. 6, 2016.

[9] K. Teeuwen, B. J. L. Van den Branden, J. J. Koolen et al., "Three-year clinical outcome in the primary stenting of totally occluded native coronary arteries III (PRISON III) trial: a 
randomised comparison between sirolimus-eluting stent implantation and zotarolimus-eluting stent implantation for the treatment of total coronary occlusions," EuroIntervention, vol. 10, no. 11, pp. 1272-1275, 2015.

[10] R. A. Henderson, S. J. Pocock, T. C. Clayton et al., "Seven-year outcome in the RITA-2 trial: coronary angioplasty versus medical therapy," Journal of the American College of Cardiology, vol. 42, no. 7, pp. 1161-1170, 2003.

[11] C P Commission, Pharmacopoeia of the People's Republic of China, 2010 edition, China Medical Science and Technology Press, Beijing, China, 2010.

[12] Y. Q. Li, M. Jin, and S. L. Qiu, "Effect of Chinese herbal medicine for benefiting qi and nourishing yin to promote blood circulation on ventricular wall motion of AMI patients after revascularization," Chinese Journal of Integrated Traditional and Western Medicine, vol. 29, no. 4, pp. 300-304, 2009.

[13] L. Zhang, J. G. Liu, Q. X. Zhang et al., "Effect of Xinyue capsule on expression of osteopontin and tenoglycoprotein in ischemic myocardium in rats after myocardial infarction," Chinese Pharmacology Bulletin, vol. 29, no. 12, pp. 1689-1695, 2013.

[14] C. Wang, Y. Z. Li, X. R. Wang, Z. R. Lu, D. Z. Shi, and X. H. Liu, "Panax quinquefolium saponins reduce myocardial hypoxia-reoxygenation injury by inhibiting excessive endoplasmic reticulum stress," Shock (Augusta, Ga.), vol. 37, no. 2, pp. 228-233, 2012.

[15] K. Knobloch, U. Yoon, and P. M. Vogt, "Preferred reporting items for systematic reviews and meta-analyses (PRISMA) statement and publication bias," Journal of Cranio-Maxillofacial Surgery, vol. 39, no. 2, pp. 91-92, 2011.

[16] A. Liberati, D. G. Altman, J. Tetzlaff et al., "The PRISMA statement for reporting systematic reviews and meta-analyses of studies that evaluate health care interventions: explanation and elaboration," Annals of Internal Medicine, vol. 151, no. 4, pp. W65-W94, 2009.

[17] W. B. Cao, L. L. Chen, L. N. Yue et al., "Clinical study of Xinyue capsule on acute coronary syndrome complicated with diabetes after intervention," World Journal of Integrated Chinese and Western Medicine, vol. 12, no. 3, pp. 410-413, 2017.

[18] J. H. Chen, Y. Han, and X. F. Wang, "Effects of Chinese herbs on left ventricular remodeling and cardiac function after percutaneous coronary intervention in patients with acute coronary syndrome," Shanxi Traditional Chinese Medicine, vol. 7, pp. 802-803, 2015.

[19] A. L. Du, C. H. Liu, J. Z. Song et al., "Effect of Xinyue capsule on cardiac function in patients with AMI after PCI and its possible mechanism," Shandong Medicine, vol. 60, no. 4, pp. 17-21, 2020.

[20] H. Y. Liu, C. Q. Wang, Y. S. Xie et al., "Effect of Xinyue capsule on prognosis of patients with acute coronary syndrome after intervention," Chinese Patent Medicine, vol. 37, no. 6, pp. 1191-1196, 2015.

[21] H. Y. Liu, "Protective effect for Chinese herbs for supplementing qi and nourishing yin and activating blood circulation on heart function in patients with acute coronary syndrome after percutaneous coronary intervention," China Academy of Chinese Medical Sciences, pp. 1-132, 2010.

[22] M. Guo, P. Wang, J. Du et al., "Xinyue capsule in patients with stable coronary artery disease after percutaneous coronary intervention: a multicenter, randomized, placebo-controlled trial," Pharmacological Research, vol. 158, 2020.

[23] S. L. Wang, C. L. Wang, P. L. Wang et al., "Combination of Chinese herbal medicines and conventional treatment versus conventional treatment alone in patients with acute coronary syndrome after percutaneous coronary intervention (5C trial): an open-label randomized controlled, multicenter study," Evidence-Based Complementary and Alternative Medicine, vol. 2013, Article ID 741518, 8 pages, 2013.

[24] H. Zhang and N. Wang, "Effects of traditional Chinese medicine on left ventricular remodeling and cardiac function after percutaneous coronary intervention in patients with acute coronary syndrome," World Chinese Medicine, vol. 12, no. 12, pp. 2984-2987, 2017.

[25] Z. H. Zhao, Before and after Percutaneous Coronary Intervention Syndrome Investigation and Intervention of Chinese Medicine Clinical PCI Patients with Coronary Heart Disease, Changchun University of Chinese Medicine, Changchun, China, 2016.

[26] G. W. Reed, J. E. Rossi, and C. P. Cannon, "Acute myocardial infarction,” The Lancet, vol. 389, no. 10065, pp. 197-210, 2017.

[27] F. Sanchis-Gomar, C. Perez-Quilis, R. Leischik, and A. Lucia, "Epidemiology of coronary heart disease and acute coronary syndrome," Annals of Translational Medicine, vol. 4, no. 13, p. 256, 2016.

[28] D. M. Kolansky, "Acute coronary syndromes: morbidity, mortality, and pharmacoeconomic burden," The American Journal of Managed Care, vol. 15, no. 2, pp. S36-S41, 2009.

[29] L. W. Qi, C. Z. Wang, and C. S. Yuan, "Ginsenosides from American ginseng: chemical and pharmacological diversity," Phytochemistry, vol. 72, no. 8, pp. 689-699, 2011.

[30] M. Karmazyn, M. Moey, and X. T. Gan, "Therapeutic potential of ginseng in the management of cardiovascular disorders," Drugs, vol. 71, no. 15, pp. 1989-2008, 2011.

[31] C. L. Wang, D. Z. Shi, and H. J. Yin, "Effect of Panax quinquefolius saponin on angiogenesis and expressions of VEGF and bFGF in myocardium of rats with acute myocardial infarction," Zhongguo Zhong Xi Yi Jie He Za Zhi, vol. 27, no. 4, pp. 331-334, 2007.

[32] A. P. Lu, J. P. Liu, D. Lu, and P. Y. Li, "Effects of Panax quinquefolium saponins on hemodynamics and myocardial ischemia in dogs with coronary artery ligation," Journal of Jilin University (Medical Edition), vol. 32, no. 3, pp. 383-386, 2006.

[33] G. L. An, X. F. Yu, S. C. Qu et al., "Protective effect of Panax quinquefolium leaf 20S-ginsenoside on experimental myocardial ischemia in rats," Jilin Traditional Chinese Medicine, vol. 25, no. 1, pp. 48-49, 2005.

[34] H. J. Yin, Y. Zhang, Y. R. Jiang et al., "Effects of Panax quinquefolium total saponins on apoptosis and apoptosisrelated gene expression in acute myocardial infarction rats," Zhongguo Zhong Xi Yi Jie He Za Zhi, vol. 25, no. 3, pp. 232-235, 2005.

[35] L. X. Guan, X. Yi, S. J. Yang et al., "The effect of Panax quinquefolium saponin on $\mathrm{Ca}^{2+}$ influx of rat cardiomyocytes," Chinese Pharmacology and Clinical Science, vol. 20, no. 6, pp. 8-9, 2004. 